\title{
IX
}

\section{EDUCATION IN THE TREATMENT OF SYPHILIS}

THE American Social Hygiene Association announces a miniature edition $\left(8 \frac{1}{2} \times\right.$ II inches) of the exhibit on the TREatment of SyPHILIS shown in the American Medical Association's Scientific Exhibit in Cleveland in June I934. The exhibit includes twenty-four charts made from a study of 8,000 cases at Johns Hopkins University, University of Michigan, The Mayo Clinic, University of Pennsylvania and Western Reserve University, in cooperation with the United States Public Health Service. This material should be useful in a variety of ways, as for example :-

I. For the instruction of medical students. It would be advantageous to place a copy of this handy exhibit in the hands of each senior medical student, or at least to display the exhibit for students to study.

2. For talks to medical societies. For this purpose the small charts may be set up as an exhibit or lantern slides could be made of each chart.

3. For instruction of nurses, social workers and others, who should know the important new facts which have been brought out by the co-operative clinics study.

Price is $30 \mathrm{c}$. a set, $\$ 3.00$ a dozen sets, post paid.

Special statements by Drs. Stokes, O'Leary, Wile, Moore and Cole, regarding the treatment of syphilis, have been prepared to accompany this exhibit. The price for each collection of statements is Io c. a set, $80 \mathrm{c}$. a dozen sets, post paid.

The charts illustrate the following :-

I. Mucocutaneous relapse during lapse of treatment, according to stage in which treatment was begun.

2. A. Site of mucocutaneous relapse lesions. B. Time relation of mucocutaneous relapse.

3. Comparison of treatment in 204 mucocutaneous relapses.

4. Relation of arsphenamine to the prevention of mucocutaneous relapse.

5. The sites of secondary lesions in 2,269 patients.

6. Incidence of early asymptomatic neurosyphilis.

7. Incidence of asymptomatic neurosyphilis according to stage of disease in which treatment was begun.

v.D. 


\section{BRITISH JOURNAL OF VENEREAL DISEASES}

8. Relation of blood Wassermann fastness to spinal fluid abnormalities in early syphilis.

9. Positive dark-field examinations by stages of early syphilis.

Io. Treatment methods.

II. Comparative effectiveness of treatment methods.

I2. Comparison of effectiveness of treatment methods in securing Wassermann reversals in one year.

13. Effect of prolonged treatment on satisfactory results.

14. Percentage of satisfactory and unsatisfactory results obtained with indicated amount of treatment.

I5. The value of X-ray of the cardiovascular stripe in clinically latent syphilis.

I6. The prognostic value of negative spinal fluid in latent syphilis.

I7. Frequency of symptomless infection.

I8. Outcome of pregnancy in untreated latent syphilis.

I9. Effect of treatment of syphilitic pregnant women with negative Wassermanns.

20. Effect of treatment of syphilitic pregnant women.

2I. Results of treatment in latent syphilis, continuous versus intermittent or irregular treatment.

22. Results of treatment in latent syphilis by gross amount of treatment given.

23. Results of treatment in latent syphilis according to the total length of observation.

24. Influence of Wassermann fastness on the tendency toward clinical relapse.

An idea of the nature of the Charts may perhaps be obtained from Figs. I and 2, which illustrate Charts Nos. I4 and I8.

\section{PERCENTAGE OF SATISFACTORY AND UNSATISFACTORY RESULTS OBTAINED WITH INDICATED AMOUNT OF TREATMENT}

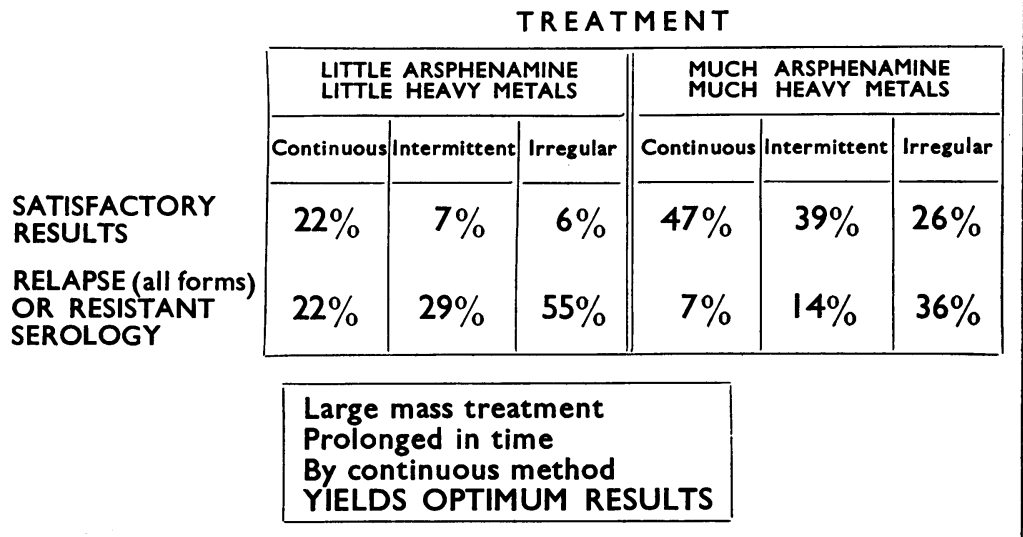

FIG. I. 


\section{EDUCATION IN TREATMENT OF SYPHILIS}

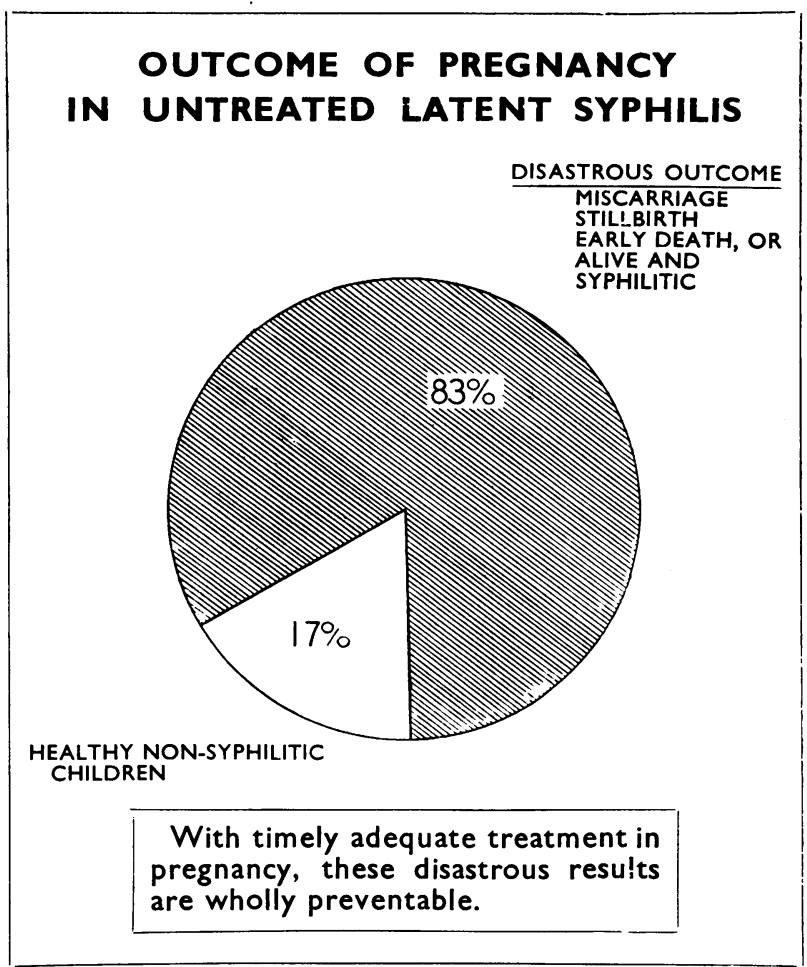

FIG. 2.

The titles of the special statements on the treatment of syphilis referred to above are as follows :-

I. Some Personal Impressions of Present-day SYPHILOTHERAPY

John M. Stokes, M.D.

II. High Points in the Management of Neurosyphilis Paul A. O'Leary, M.D.

III. Special Considerations in the Treatment of the INDIVIDUAL SUfFERING WITH LATENT ASYMptoMATIC SYPHILIS

$$
\text { Udo J. Wile, M.D. }
$$

IV. Principles of Treatment of Cardiovascular SyPHILIS

Joseph Earle Moore, M.D.

V. The Effect of Syphilis on Pregnancy and ON THE CHILD

Harold N. Cole, M.D. 